
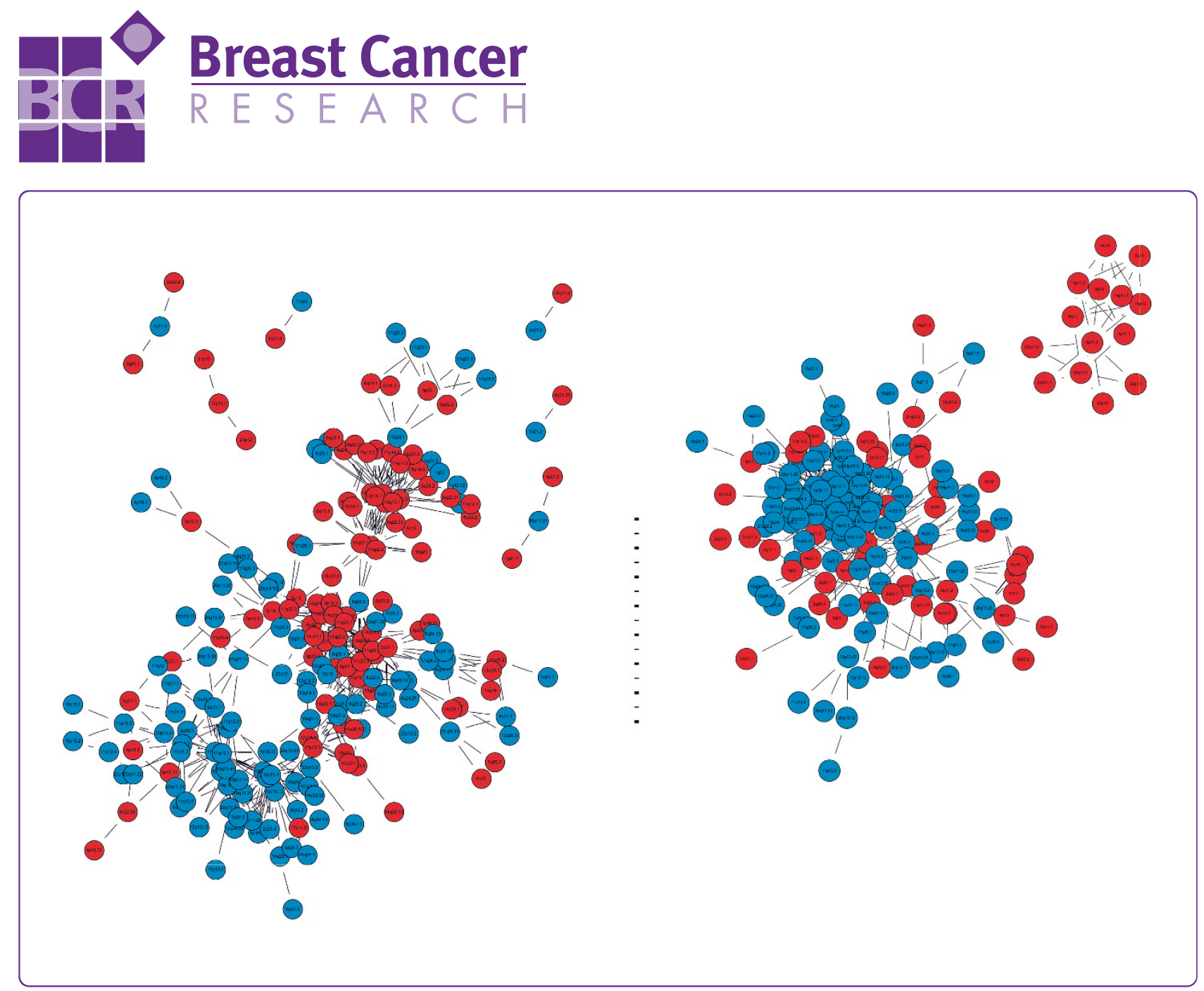

\title{
Genomic and phenotypic analysis of BRCA2 mutated breast cancers reveals co-occurring changes linked to progression
}

Stefansson et al. 


\title{
Genomic and phenotypic analysis of $B R C A 2$ mutated breast cancers reveals co-occurring changes linked to progression
}

\author{
Olafur A Stefansson ${ }^{1}$, Jon G Jonasson ${ }^{1,2,4}$, Kristrun Olafsdottir ${ }^{2}$, Hordur Bjarnason ${ }^{1}$, Oskar Th Johannsson ${ }^{3}$, \\ Sigridur K Bodvarsdottir ${ }^{1}$, Sigridur Valgeirsdottir ${ }^{5}$ and Jorunn E Eyfjord ${ }^{1 *}$
}

\begin{abstract}
Background: Inherited mutations in the BRCA2 gene greatly increase the risk of developing breast cancer. Consistent with an important role for $B R C A 2$ in error-free DNA repair, complex genomic changes are frequently observed in tumors derived from BRCA2 mutation carriers. Here, we explore the impact of DNA copy-number changes in BRCA2 tumors with respect to phenotype and clinical staging of the disease.
\end{abstract}

Methods: Breast tumors $(n=33)$ derived from BRCA2 999del5 mutation carriers were examined in terms of copynumber changes with high-resolution aCGH (array comparative genomic hybridization) containing 385 thousand probes (about one for each $7 \mathrm{kbp}$ ) and expression of phenotypic markers on TMAs (tissue microarrays). The data were examined with respect to clinical parameters including TNM staging, histologic grade, S phase, and ploidy.

Results: Tumors from BRCA2 carriers of luminal and basal/triple-negative phenotypes (TNPs) differ with respect to patterns of DNA copy-number changes. The basal/TNP subtype was characterized by lack of pRb (RB1) coupled with high/intense expression of p16 (CDKN2A) gene products. We found increased proportions of Ki-67-positive cells to be significantly associated with loss of the wild-type (wt) BRCA2 allele in luminal types, whereas BRCA2wt loss was less frequent in BRCA2 tumors displaying basal/TNP phenotypes. Furthermore, we show that deletions at 13q13.1, involving the BRCA2wt allele, represents a part of a larger network of co-occurring genetic changes, including deletions at 6q22.32-q22.33, 11q14.2-q24.1, and gains at 17q24.1. Importantly, copy-number changes at these BRCA2-linked networking regions coincide with those associated with advanced progression, involving the capacity to metastasize to the nodes or more-distant sites at diagnosis.

Conclusions: The results presented here demonstrate divergent paths of tumor evolution in BRCA2 carriers and that deletion of the wild-type BRCA2 allele, together with co-occurring changes at $6 \mathrm{q}, 11 \mathrm{q}$, and $17 \mathrm{q}$, are important events in progression toward advanced disease.

\section{Introduction}

Germline mutations in one allele of the BRCA2 tumorsuppressor gene confer greatly increased risk of developing breast cancer [1]. The BRCA2 gene is known to be involved in error-free DNA repair of double-strand breaks (DSBs) through homologous recombination (HR) [2]. Defects in this mechanism lead to repair of DSBs by error-prone nonhomologous end joining (NHEJ) or

\footnotetext{
* Correspondence: jorunne@hi.is

${ }^{1}$ Cancer Research Laboratory, Faculty of Medicine, University of Iceland,

Vatnsmyrarvegur 16, Reykjavik, Iceland

Full list of author information is available at the end of the article
}

single-strand annealing (SSA). The use of error-prone mechanisms for DSB repair can result in genetic changes involving rearrangements and sequence modification at the damaged sites [3]. In this relation, it has been shown that chromosomal instability arises after inactivation of murine Brca2 gene, which is in agreement with complex chromosomal changes observed in human breast tumors derived from BRCA2 carriers $[4,5]$. Consistent with Knudson's two-hit hypothesis for tumor suppression, loss of the wild-type (wt) BRCA2 allele has been described as an essential event in tumor initiation in BRCA2 carriers [6]. This notion has,
C Biomed Central

(c) 2011 Stefansson et al.; licensee BioMed Central Ltd. This is an open access article distributed under the terms of the Creative Commons Attribution License (http://creativecommons.org/licenses/by/2.0), which permits unrestricted use, distribution, and reproduction in any medium, provided the original work is properly cited. 
however, recently been questioned with data demonstrating that loss of Brca2 heterozygosity is not a required event in murine models of familial pancreatic cancer and, for human carriers of the BRCA2 999del5 mutation, that loss of heterozygosity (LOH) might not be needed to promote carcinogenesis in the pancreas [7]. In addition, breast cancers arising in $B R C A 1$ and $B R C A 2$ mutation carriers are heterogenic for $\mathrm{LOH}$, suggesting haploinsufficient effects in pathogenesis [8].

Genome-wide expression analyses of breast cancers have led to the identification of biologically and clinically relevant subtypes (that is, luminal-A (LumA), luminal-B (LumB), basal-like, HER2, and normal-like) [9]. The identified subtypes have shown substantial differences with respect to copy-number changes, suggesting that their development adheres to changes in distinct sets of genes, leading to diverging tumor-evolution pathways $[10,11]$. Of these, the luminal subtypes comprise the majority of all cases (60\% to $70 \%)$, both characterized by expression of GATA3-regulated genes. The LumB subtype differs from LumA by high expression of proliferation-associated genes with increased levels of MKI67 (Ki-67) as a prominent feature, and are associated with less-favorable disease outcome [12]. Basal-like breast cancers are characterized by expression of genes that pertain to the basal layer of cells in normal mammary glands, such as CK5/6 and CK14. The basal-like and HER2 subtypes are both highly proliferative, poorly differentiated, and, in concordance, show the least-favorable disease outcome [13]. Tumors arising in BRCA2 germline mutation carriers mostly display luminal phenotypes of high histologic grade and have prominent expression of proliferation markers, suggesting similarities to the LumB subtype [14]. Relatively few BRCA2 tumors have been profiled for copy-number changes, and have mostly been studied by using low-resolution array design, resulting in relatively crude patterns and lack of clarity in identification of key drivers. In our previous report, we found that $B R C A 2$ tumors often show highly complex genomes coupled with a unique pattern of copy-number changes [15]. To follow up on these results, we have studied copy-number changes in a larger number of BRCA2 tumors by high-resolution array-comparative hybridization (aCGH) microarrays containing 385 thousand probes (about one for each 7 $\mathrm{kbp}$ ) in breast tumors derived from $B R C A 2$ germline mutation carriers $(n=33)$ combined with analysis of phenotypic markers by immunohistochemistry (IHC) on tissue microarrays (TMAs). The purpose of the study was to characterize the spectrum of copy-number changes in tumors obtained from $B R C A 2$ carriers with respect to phenotype and clinical parameters.

\section{Materials and methods Study group}

Tumor DNA samples $(n=33)$ were derived from patients carrying the 999del5 BRCA2 germline mutation [16]. The tumors were macroscopically examined by a pathologist to identify portions with invasive tumor cells. DNA extraction was performed on freshly frozen tumor portions by following protocols based on standard procedures by using phenol-chloroform and proteinase $\mathrm{K}$. Clinical parameters, including TNM staging and histologic grade, were obtained from the Department of Pathology, Landspitali University, and are given in Additional File 1. Data on S phase and ploidy, obtained with flow cytometry, were available for 30 of the 33 breast tumors analyzed in this study. Data on patient relapse, that is, events of recurrences or metastases after diagnosis and treatment, were obtained from Landspitali University Hospital. This work was carried out according to permits from the Icelandic Data Protection Commission (2006050307) and Bioethics Committee (VSNb2006050001/03-16). Informed consent was obtained from all patients.

\section{Array-comparative genomic hybridization}

Copy-number changes were studied with high-resolution 385 K oligonucleotide CGH microarrays (Roche NimbleGen, Inc., Reykjavik, Iceland) containing 385 thousand probes covering the human genome with about one probe for each $7 \mathrm{kbp}$. DNA derived from tumor- and normal blood samples from the same individual were Cy3 and Cy5 labeled, respectively. Sample labeling and hybridizations were carried out according to protocols developed by the manufacturer (NimbleGen Arrays User's Guide-CGH Analysis; Roche NimbleGen, Inc., Reykjavik, Iceland). The aCGH data are available online from ArrayExpress [17] under the accession number ETABM-1199.

Fine-tiling aCGH analysis was performed by using the $385 \mathrm{~K}$ oligonucleotide CGH microarrays covering chromosome 6 with about one probe for each $400 \mathrm{bp}$ (Roche NimbleGen, Inc.), following the manufacturers protocols for sample labeling and hybridization (Roche NimbleGen).

\section{Tissue microarrays and expression analysis by immunohistochemistry}

TMAs construction and their application in expression analysis by immunohistochemistry (IHC) have been described previously [15]. Tumors were assigned to molecular subtypes by using the five-biomarker scheme described in Cheang et al. [13] by expression of estrogen receptor (ER), progesterone receptor (PR), human epidermal growth factor receptor 2 (HER-2), epidermal 
growth factor receptor (EGFR), and cytokeratin 5/6 (CK5/6). Expression of ER and PR were scored positive (IHC score $\geq 1^{+}$) when IHC staining was observed in more than $1 \%$ of tumor cell nuclei. HER-2 positivity was scored for strong membranous staining (IHC score $3^{+}$), whereas EGFR was scored positive for any, weak or strong, membranous staining (IHC score $\geq 1^{+}$). Expression of CK5/6 was defined as positive when cytoplasmic and/or membranous staining was observed and otherwise considered negative. Hormone-receptor-positive tumors, those positive for either ER or PR, were assigned to the luminal subtype. Tumors negative for ER, PR, and HER-2 were categorized as triple-negative phenotype (TNP), whereas ER- and PR-negative tumors displaying HER-2 positivity (IHC $3^{+}$) were assigned to the HER2 subtype. Basal-like phenotype was assigned to triple-negative tumors displaying expression of either EGFR or CK5/6. Estimates for the expression of Ki-67 (MKI67), cyclin-D1 (CCND1), and topoisomerase II alpha (TOP2A) gene products represent counts for the proportion of positive tumor cells, based on nuclear expression, reported on a scale from 0.0 to 1.0 within intervals of 0.05 . Luminal tumors showing Ki-67 expression $\geq 0.14$ were assigned to the luminal B subtype, whereas the remaining part was considered luminal A [12]. Expression of p16 (CDKN2A) and pRb (RB1) was scored on a discontinuous scale based on counts for the proportion of tumor cells showing nuclear expression (that is, $0(<10 \%), 1^{+}$(10\% to $\left.25 \%\right), 2^{+}(25 \%$ to $50 \%)$, and $3^{+}(>50 \%)$. The antibodies and dilutions used in IHC expression analysis are listed in Additional File 2.

\section{TaqMan BRCA2 allele-specific quantitative PCR}

The proportion of $B R C A 2$ wild-type (wt) alleles was quantitatively measured relative to 999del5 BRCA2 mutated alleles in tumor DNA samples by quantitative polymerase chain reaction (PCR) (7500 Realtime PCR system; Applied Biosystems) with a TaqMan method by using a single $B R C A 2$-specific, minor groove-binding probe (MGB-probe) 5 '-end-labeled with FAM and a nonfluorescent quencher (NFQ) at the 3' end, a single $B R C A 2$-specific forward primer, and two allele-specific reverse primers. Therefore, the PCR for wt and mutant alleles was performed in separate wells. The qPCR assay primers and TaqMan-MGB probe were as follows: Forward primer: 5'-CATGATGAAAGTCGTAAGAAA-3', Reverse primer (mut): 5'-CATGACTTGCAGCTTC TCTTTGTG-3', Reverse primer (wt): 5'-CATGACTTGCAGCTTCTCTTTGAT-3', TaqMan-MGB probe: 5'TTTATCGCTTCTGTGACA-3'. Reactions were at a 12$\mu \mathrm{l}$ final volume per well, each containing: TaqMan-MGB at $50 \mathrm{n} M$, forward and reverse primers at $0.5 \mathrm{n} M$ each, $6 \mu \mathrm{l}$ TaqMan Universal PCR Master Mix (Applied Biosystems, Pn. 4304437), and $0.25 \mu \mathrm{g}$ of sample DNA, with $\mathrm{H}_{2} \mathrm{O}$ to final volume. The PCR: Step $(\mathrm{S}) 1: 50^{\circ} \mathrm{C}$ for 2 minutes, $\mathrm{S} 2$ : $95^{\circ} \mathrm{C}$ for 10 minutes, $\mathrm{S} 3$ : $95^{\circ} \mathrm{C}$ for $15 \mathrm{sec}-$ onds, S4: $60^{\circ} \mathrm{C}$ for 1 minute, with $\mathrm{S} 3$ and S4 were repeated for 40 cycles. The $B R C A 2$ wt- to mutant-allele ratios were quantified by measuring differences in fluorescence intensity of FAM performed in duplicate, and the $\mathrm{Ct}$ values (number of cycles to reach intensity threshold) were averaged. Ct measures with standard deviation higher than 0.5 ( $\mathrm{SD}>0.5$ ) were rejected and remeasured. The wild-type to mutant-allele ratios were calculated to wt/allele frequencies by the following equation:

$$
\begin{aligned}
& \text { Frequency of allele }{ }_{1}=1 /\left(2^{\Delta \mathrm{Ct}}+1\right) \\
& \text { where } \Delta \mathrm{Ct}=(\mathrm{Ct} \text { of allele } 1-\mathrm{Ct} \text { of allele })_{2} \text { [18]. }
\end{aligned}
$$

\section{Statistical analysis and data mining of aCGH data}

Preprocessing and segmentation of the aCGH data were carried out as described previously [15]. Normalized $\log _{2}$ ratios were replaced with corresponding segment means for each probe represented on the arrays to derive a segmented profile for each tumor. These data were used as input for SAMr (significance analysis of microarrays for R) in two-class or quantitative analysis, in which repeated permutations are used to address multiple testing [19].

Genetic networks represent a set of associated copynumber changes (links) between distinct regions (nodes) of the genome. Here, the average of segmented aCGH $\log _{2}$ ratios was computed for each of 811 cytobands with the nucleotide cytoband-locations downloaded by using the UCSC table browser [20]. The pair-wise cytoband-cytoband associations were then determined by hypothesis testing for Spearman's rho (Stats package in $\mathrm{R})$. The $P$ values for each of these comparisons were then adjusted for multiple testing by the Holm procedure (Multitest package in Bioconductor for R). Links were then established for associations with $P_{\text {adj }}<0.001$, while also having minimum event frequency of $25 \%$. The associations, or "genetic links," represent nonrandom patterns of co-occurring copy-number changes. We then split the links into sets of inter- and intrachromosomal links involving associations between distinct chromosomes (inter), or associations between distinct arms on the same chromosome (intra), respectively. The resulting networks of co-occurring genetic changes were visualized as undirected node-and-edge graphs by making use of the Rgraphviz package in Bioconductor for R.

\section{Results}

\section{Breast cancer subtypes in BRCA2 mutated tumors}

Thirty-three female breast cancer patients carrying the same 999del5 BRCA2 germline mutation constituted the 
study group analyzed with array CGH (comparative genomic hybridization). The year of diagnosis was between 1989 and 1999, with the mean age of 50 years (standard deviation $(\mathrm{SD})=12.2)$ (Additional File 1). Of the 33 tumors analyzed with aCGH, 32 were available on tissue microarrays (TMAs). Expression analysis of subtype-specific biomarkers, that is, ER, PR, HER-2, Ki67, CK5/6, and EGFR, was performed on TMAs with IHC. The results show that most BRCA2 tumors express luminal markers (24 of 32; $75.0 \%$ ), of which the majority subcategorize as luminal B (16 of $24 ; 67 \%)$ rather than luminal A (eight of 24; 33.3\%) (Table 1). Notably, none of the 32 BRCA2 tumors displayed overexpression or high-level amplification of the human epidermal growth factor receptor 2 (HER2) oncogene (Table 1). Of the eight hormone-receptor negative BRCA2 tumors, all but one was subcategorized as basal-like (seven of eight, 87.5\%), of which four displayed EGFR expression, and five were positive for CK5/6 (Table 1).

MKI67 (Ki-67) gene products tightly associate with cellular proliferation and are often used to estimate tumor growth rates [21]. Counting the number of tumor cells positive for $\mathrm{Ki}-67$ against the total number of tumor cells reveals generally higher proliferation rates

Table 1 Phenotypic characterization of breast tumors derived from BRCA2 germline mutation carriers

\begin{tabular}{|c|c|c|c|}
\hline Biomarkers for definition of phenotypes & 0 & $\mathrm{I}-\mathrm{II}$ & III \\
\hline ER & $8(25 \%)$ & $7(22 \%)$ & $17(53 \%)$ \\
\hline PR & $12(37 \%)$ & $14(44 \%)$ & $6(19 \%)$ \\
\hline HER2 & $22(69 \%)$ & $10(31 \%)$ & $0(0)$ \\
\hline \multicolumn{4}{|c|}{ Cellular proliferation; The proportion of cells positive for Ki-67 } \\
\hline Ki-67 & $0-14 \%$ (1st Qu.) & $>14 \%-35 \%(\mathrm{IQR})$ & $>35 \%$ (3rd Qu.) \\
\hline Luminal & $8(33 \%)$ & $14(58 \%)$ & $2(8 \%)$ \\
\hline Triple-negative & $0(0)$ & $3(37 \%)$ & $\begin{array}{l}5(63 \%) \\
X^{2} \text { test; } P=0.004\end{array}$ \\
\hline \multicolumn{4}{|l|}{ Expression of basal features } \\
\hline EGFR & 0 & 1 & $\geq$ II \\
\hline Luminal & $22(96 \%)$ & $1(4 \%)$ & $0(0)$ \\
\hline Triple-negative & $4(50 \%)$ & $1(13 \%)$ & $\begin{array}{l}3(37 \%) \\
X^{2} \text { test; } P=0.004\end{array}$ \\
\hline CK5/6 & Negative & Positive & \\
\hline Luminal & $24(100 \%)$ & 0 & \\
\hline \multirow[t]{2}{*}{ Triple-negative } & $3(37 \%)$ & $5(63 \%)$ & \\
\hline & & & $X^{2}$ test $; P=0.0003$ \\
\hline \multicolumn{4}{|l|}{ pRb/p16 pathway } \\
\hline p16 (CDKN2A) & 0 & $I-I I$ & III \\
\hline Luminal A & $3(38 \%)$ & $4(50 \%)$ & $1(12 \%)$ \\
\hline Luminal B & $9(60 \%)$ & $5(33 \%)$ & $1(7 \%)$ \\
\hline Triple-negative & 0 & $1(12 \%)$ & $\begin{array}{l}7(88 \%) \\
X^{2} \text { test; } P=0.0007\end{array}$ \\
\hline Cyclin-D1 (CCND1) & $0-15 \%$ (1st Qu.) & $>15 \%-75 \%$ (IQR) & > 75\% (3rd Qu.) \\
\hline Luminal A & $1(12 \%)$ & $4(50 \%)$ & $3(38 \%)$ \\
\hline Luminal B & $1(6 \%)$ & $8(50 \%)$ & $7(44 \%)$ \\
\hline Triple-negative & $6(75 \%)$ & $2(25 \%)$ & $\begin{array}{l}0 \\
X^{2} \text { test } ; P=0.005\end{array}$ \\
\hline $\mathrm{pRb}(\mathrm{RB} 1)$ & $\mathbf{0}$ (Negative) & I (Positive) & \\
\hline Luminal A & $1(13 \%)$ & 7 (87\%) & \\
\hline Luminal B & $2(13 \%)$ & $14(87 \%)$ & \\
\hline \multirow[t]{2}{*}{ Triple-negative } & $4(50 \%)$ & $4(50 \%)$ & \\
\hline & & & $X^{2}$ test $; P=0.085$ \\
\hline \multicolumn{4}{|l|}{ Morphologic features } \\
\hline Histologic grade & 1 & II & III \\
\hline Luminal & $2(8 \%)$ & $11(44 \%)$ & $12(48 \%)$ \\
\hline Triple-negative & $1(12 \%)$ & $1(12 \%)$ & $\begin{array}{l}6(75 \%) \\
X^{2} \text { test, } P=0.27\end{array}$ \\
\hline
\end{tabular}


among triple-negative $B R C A 2$ tumors compared with luminal $B R C A 2$ tumors $\left(\chi^{2}\right.$ test; $P=0.004$; Table 1 ; Additional File 3). These differences coincide with high p16 (CDKN2A) $\left(\chi^{2}\right.$ test; $\left.P=0.0007\right)$, and low pRb (RB1) in the triple-negative subtype of $B R C A 2$ mutated breast tumors $\left(\chi^{2}\right.$ test; $P=0.085$ ) (Table 1 ). Increased p16 expression levels were highly correlated with decreased $\mathrm{pRb}$ levels (Spearman correlation rho $=-0.63 ; P=$ 0.0001). Accordingly, low pRb levels coupled with high $\mathrm{p} 16$, that is $\mathrm{pRb} \mathrm{b}^{\text {low }} / \mathrm{p} 16^{\text {high }}$, was commonly found in triple-negative $B R C A 2$ tumors (four of eight; $50 \%$ ), but rarely in luminal BRCA2 tumors (two of $23 ; 8.7 \%)\left(\chi^{2}\right.$ test; $P=0.043$ ) (Additional File 3 ). In contrast, the luminal subtypes of BRCA2 mutated breast tumors were associated with high expression of cyclin-D1 gene products $\left(\chi^{2} ; P=0.005\right)$ (Table 1$)$.

\section{DNA copy-number changes with respect to phenotype in BRCA2-associated tumors}

Event-frequency plots for copy-number changes in $B R C A 2$ tumors displaying luminal $\mathrm{A}$, luminal $\mathrm{B}$, and basal/TNP describe the fraction of tumors within each class, showing gains or losses in order of genomic position (Figure 1a-c). Clearly, certain events occur more

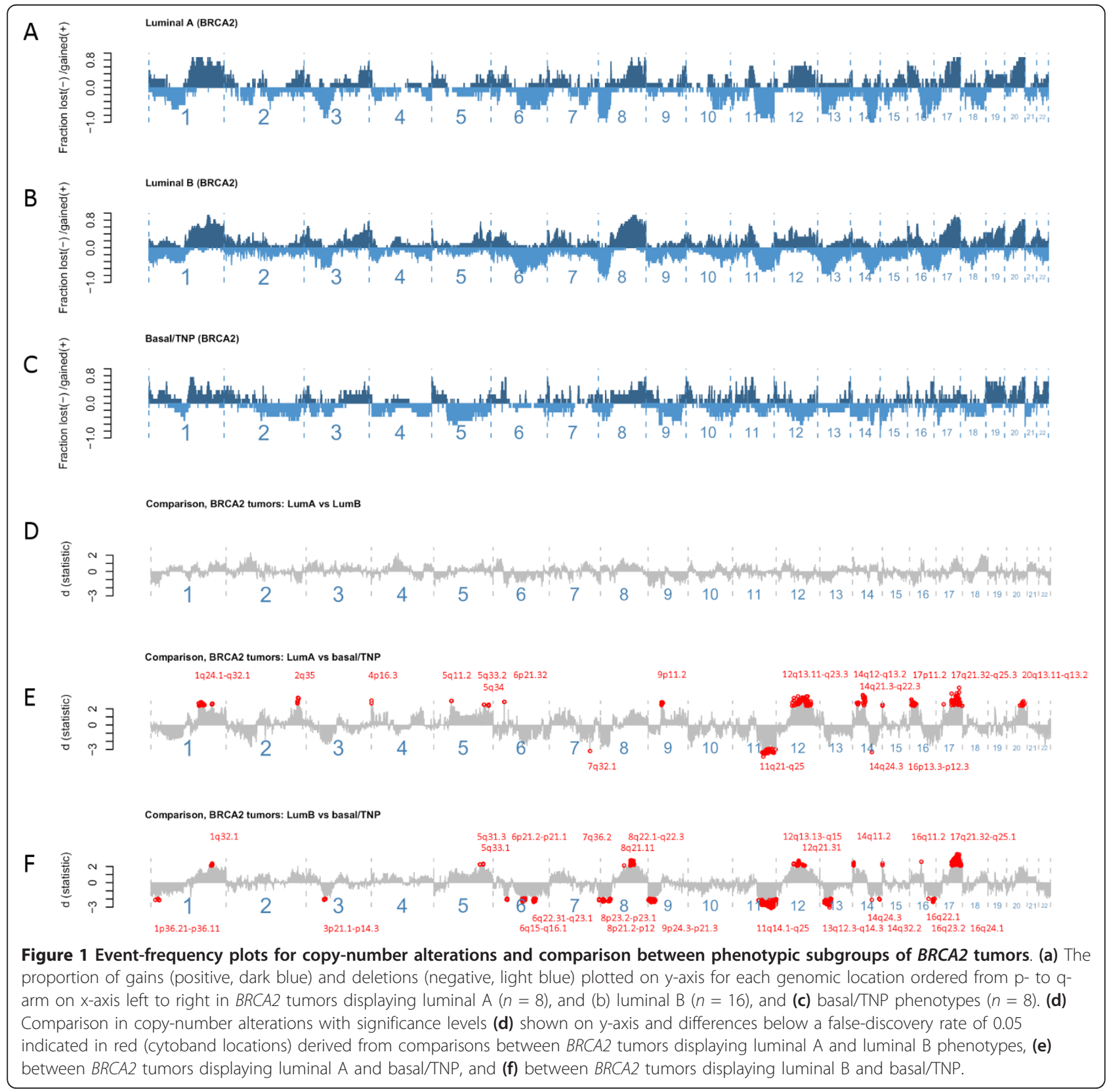


frequently in the luminal types of $B R C A 2$ tumors compared with those of basal/TNP phenotypes and vice versa. An important observation in this respect is that some changes are inversely altered between the two phenotypic subgroups (that is, luminal and TNP/basal). To illustrate this point, it can be seen that changes over 12 q predominantly occur as gains in the luminal subtypes, whereas they mostly occur as deletions in the basal/TNP subtypes (Figure 1a-c). Detailed comparison between each phenotypic subclass of $B R C A 2$ tumors shows that luminal A and B do not differ (Figure 1d). However, substantial differences were revealed between either luminal A or B when compared with TNP/basal types of BRCA2 tumors (Figure 1e, f). Some of these differences probably reflect phenotype-related effects independent of BRCA2 abnormalities (for example, the events at $5 \mathrm{q}$ and $8 \mathrm{q}$ have been described with respect to phenotype in sporadic tumors elsewhere $[10,22]$ ). However, other differences may relate to $B R C A 2$ defects; for example, deletions at 13q13.1, covering the BRCA2 gene locus, were highly prominent in $B R C A 2$ tumors of luminal $\mathrm{B}$ types compared with those displaying basal/ TNP features (Figure 1f).

Given the importance of the BRCA2 locus in this study, we specifically explored the segmented aCGH $\log _{2}$ ratios covering the $B R C A 2$ gene along with analysis of allele-specific BRCA2 loss with qPCR analysis. These methods showed strong concordance (that is, changes in aCGH $\log _{2}$ ratios at the $B R C A 2$ locus significantly correlate with estimates of $B R C A 2$ wild-type allele proportions by qPCR; Pearson correlation $r=0.69 ; P=$ 0.000025). Looking separately at each of the two BRCA2 phenotypic subgroups (luminal and basal/TNP), a clear trend toward deletion at the $B R C A 2$ locus emerged for the luminal types of $B R C A 2$ tumors, in particular, in the more-proliferative luminal B type (Figure 2a). Two individual cancer genomes analyzed by aCGH are shown to illustrate lack of deletion events affecting the $B R C A 2$
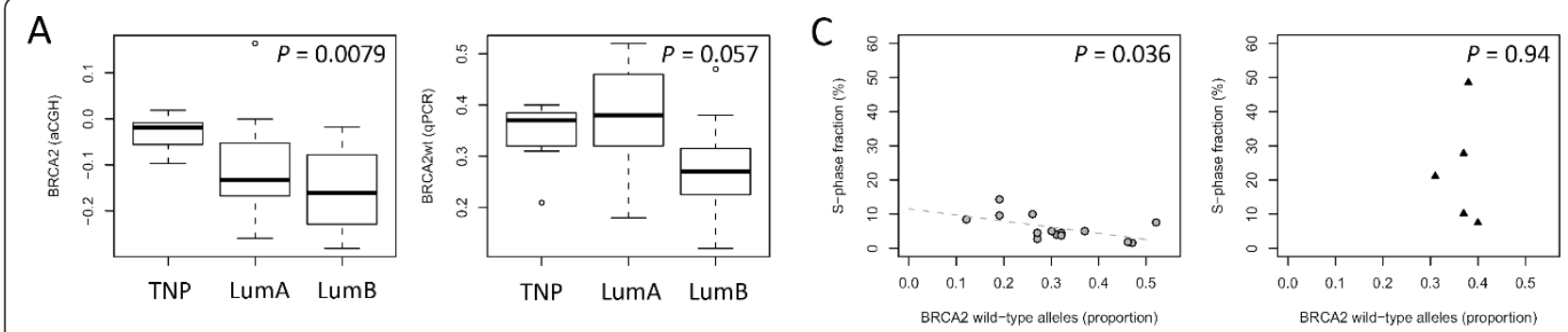

B
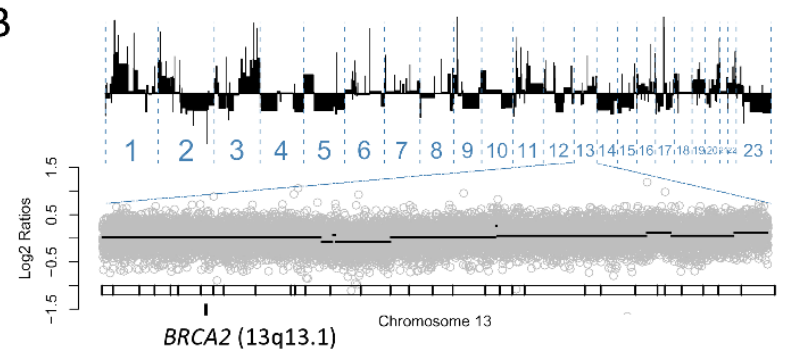

D
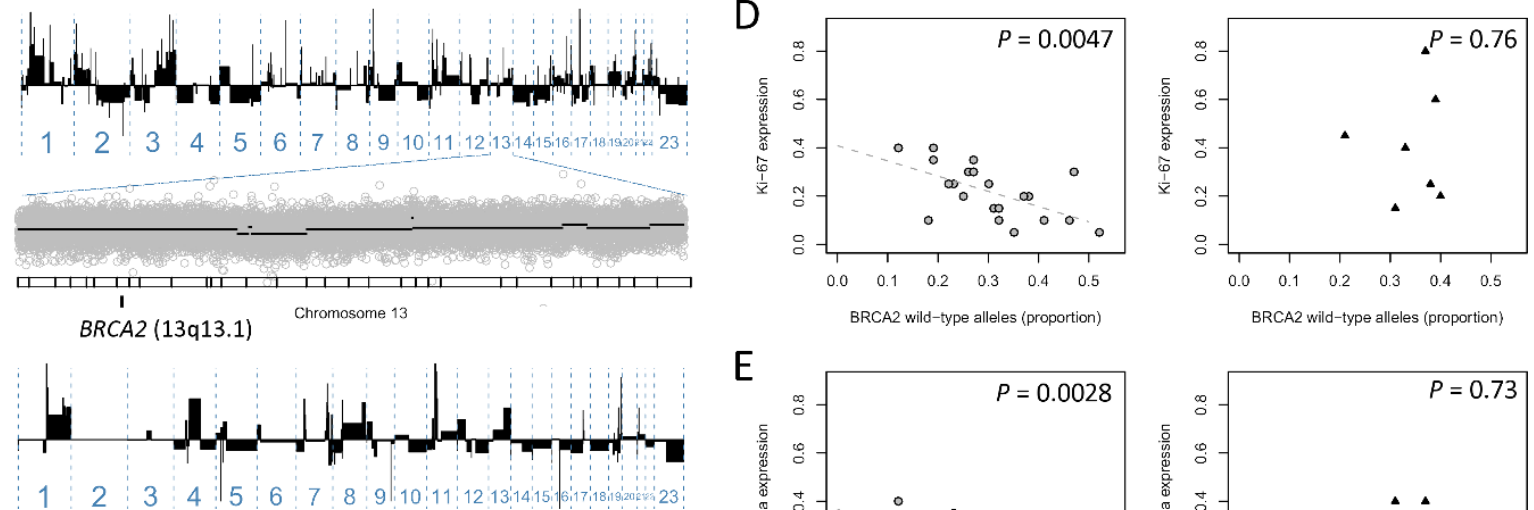

$E$
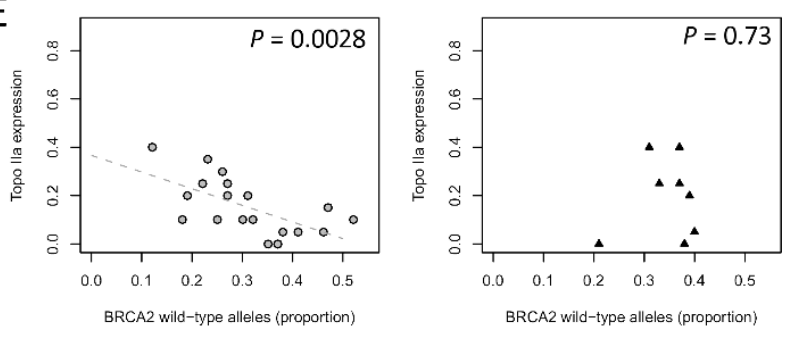

Figure 2 The effects of $B R C A 2$ deletion in phenotypic context. (a) Deletion at the BRCA2 locus measured by segmented aCGH log 2 ratios (left) and TaqMan qPCR (right) in relation to phenotype. (b) Example profiles derived from two BRCA2 tumors (a19861102, a128049) of the triplenegative subtype analyzed by using $385 \mathrm{~K}$ aCGH (about one probe for each $7 \mathrm{~kb}$ ). DNA gains or deletions are represented on the $y$-axis as black bars toward positive or negative values, respectively, in order of the chromosomal location from $p$ - to q-arm (left to right). Focused views of chromosome 13 are displayed below each of the two profiles showing $\log _{2}$ ratios (gray dots) on $y$-axis by nucleotide position on $x$-axis from $p$ arm to q-arm (left to right) with cytobands and the BRCA2 gene locus at 13q13.1 indicated as shown at the bottom of each plot. (c) S phase, (d) Ki-67, and (e) Topo lla in relation to changes at the BRCA2 gene locus, affecting the wild-type allele, in luminal- (left panel, gray circles) and triple-negative phenotypes (right panel, black triangles). 
gene locus at 13q13.1 in the TNP subtype of BRCA2 tumors (Figure $2 \mathrm{~b}$ ). To examine this further, we studied the relation on a continuous scale with markers of cellular proliferation that are S phase by flow cytometry, along with expression of proliferation-associated genes measured on a semicontinuous scale that is, Ki-67, and Topo II $\alpha$. Estimates for S-phase fractions, indicative of cells undergoing DNA replication, were found to be associated with decreased proportions of BRCA2 wildtype alleles in BRCA2 tumors of the luminal phenotype (Pearson correlation, $r=-0.56 ; P=0.036$ ) (Figure 2c). This relation was not found in $B R C A 2$ tumors displaying basal/TNP features, wherein very high proliferation rates are attained independent of deletion events over the $B R C A 2$ locus at $13 \mathrm{q} 13.1$. Expression of $\mathrm{Ki}-67$, as a measure of cellular proliferation, has the benefit of enabling stromal cells to be ignored, which is more difficult in analysis of $\mathrm{S}$ phase with flow cytometry. Estimates for the proportion of Ki-67-positive tumors cells were found to be correlated with decreased proportions of wild-type BRCA2 alleles in BRCA2 tumors displaying luminal characteristics (Pearson correlation, $r=-0.59 ; P$ $=0.0047)$, whereas the same was not found in BRCA2 tumors displaying basal/TNP phenotype (Pearson correlation, $r=0.13, P=0.76$ ) (Figure $2 \mathrm{~d}$ ). In support for the preceding, the same associations, with respect to $B R C A 2$ wild-type allele loss and phenotype, were identified for estimates of the cell-cycle associated gene product Topo II $\alpha$ (Figure 2e).

\section{Genetic networks}

DNA copy-number changes showing significant associations between distinct chromosomal regions in the set of 33 BRCA2 tumors were identified, and visualized as an undirected node-and-edge graph in which significant correlations are represented as edges, with genomic regions as nodes (Figure 3a, b; Additional File 4). This analysis identified a set of 14 cytobands involving three distinct interchromosomal links in association with the $B R C A 2$ locus at $13 \mathrm{q} 13.1$, that is, deletions at $6 \mathrm{q} 22.32$ q22.33 and 11q14.2-q24.1, along with copy-number gains at $17 \mathrm{q} 24.1$ (Figure 3b, Additional File 4). It is important to note here that the data on BRCA2wt-specific loss confirmed the links identified with respect to 6q22.32-q22.33 and 11q14.2-q24.1 (Additional File 5). Based on the BRCA2-linked networking regions (6q22.32-q22.33, 11q14.2-q24.1, 13q13.1, and 17q24.1), two subgroups were identified through cluster analysis (Figure 3c). Evidently, these subgroups differ by the degree of change over the regions identified in association with the BRCA2 gene locus. Here, measures of higher clinical staging at the time of diagnosis, involving metastasis to the lymph nodes, were more prominent in the subgroup showing changes over the BRCA2-linked networking regions (Figure 3c). Data on patient relapse were available in some of these cases, defined as an instance of subsequent metastasis or recurrence, which provided support for the hypothesis generated here that DNA copy-number changes over the BRCA2-linked networking regions promote progression toward moreadvanced forms of the disease (see Figure 3c). In all cases, metastasis to more-distant sites of the body was involved, of which all but one occurred as bone metastases. To determine whether the network of genetic changes identified in relation to the BRCA2 locus at 13q13.1 is specific for BRCA2 mutated breast cancers, we looked at our previously published data on sporadic breast cancers [15]. As expected, the BRCA2 locus at $13 q 13.1$ was not represented within the genetic networks constructed by using the same approach for sporadic breast cancers (Additional File 4).

In a two-class comparison for BRCA2 tumors with or without evidence of metastasis to the lymph nodes, or other more distant sites, loss over the BRCA2 locus at 13q13.1 was identified in this analysis as significantly associated with metastasis to the lymph nodes, along with the BRCA2-linked networking regions at $6 \mathrm{q}$ and $11 \mathrm{q}$ (Figure 4). Of these, deletions at chromosome $6 \mathrm{q}$ were the most predictive for lymph node positivity, or "metastatic capacity," with the strongest associations (significance peaks) found at 6q16.3 and 6q22.33. Looking at the frequency of copy-number changes at 6q22.33, we identified a shift toward increased frequency of deletions at a location close to the PTPRK gene, which affected four other genes, that is EEF1DP5, LAMA2, ARHGAP18, and C6orf191 (Additional File 6). Fine-tiling aCGH analysis at exon-level resolution (about one probe for each $400 \mathrm{bp}$ ) covering chromosome 6 confirmed deletions at 6q22.33 (Additional File 7 ). This analysis shows that the events at $6 \mathrm{q}$-arm occur as complex deletions confined within the $6 \mathrm{q}$ chromosomal region. Here, one of the tumors had acquired a breakpoint event located within the 6q22.33 cytoband proximal to the PTPRK gene affecting upstream regions (Additional File 7). This subregion within the $6 \mathrm{q} 22.33$ cytoband was not affected in the lymph-node-negative tumor, but rather involved a region downstream of the PTPRK gene (Additional File 7).

\section{The analysis of ploidy in BRCA2 mutated breast cancers with respect to DNA copy-number changes by aCGH}

Data available on ploidy were analyzed with respect to DNA copy-number changes to follow-up on recent results demonstrating poor disease outcome for $B R C A 2$ carriers diagnosed with breast tumors of the diploid type (Tryggvadottir et al., 2011; unpublished data). In line with the less-favorable prognosis associated with the diploid type of BRCA2 tumors, we found that BRCA2 


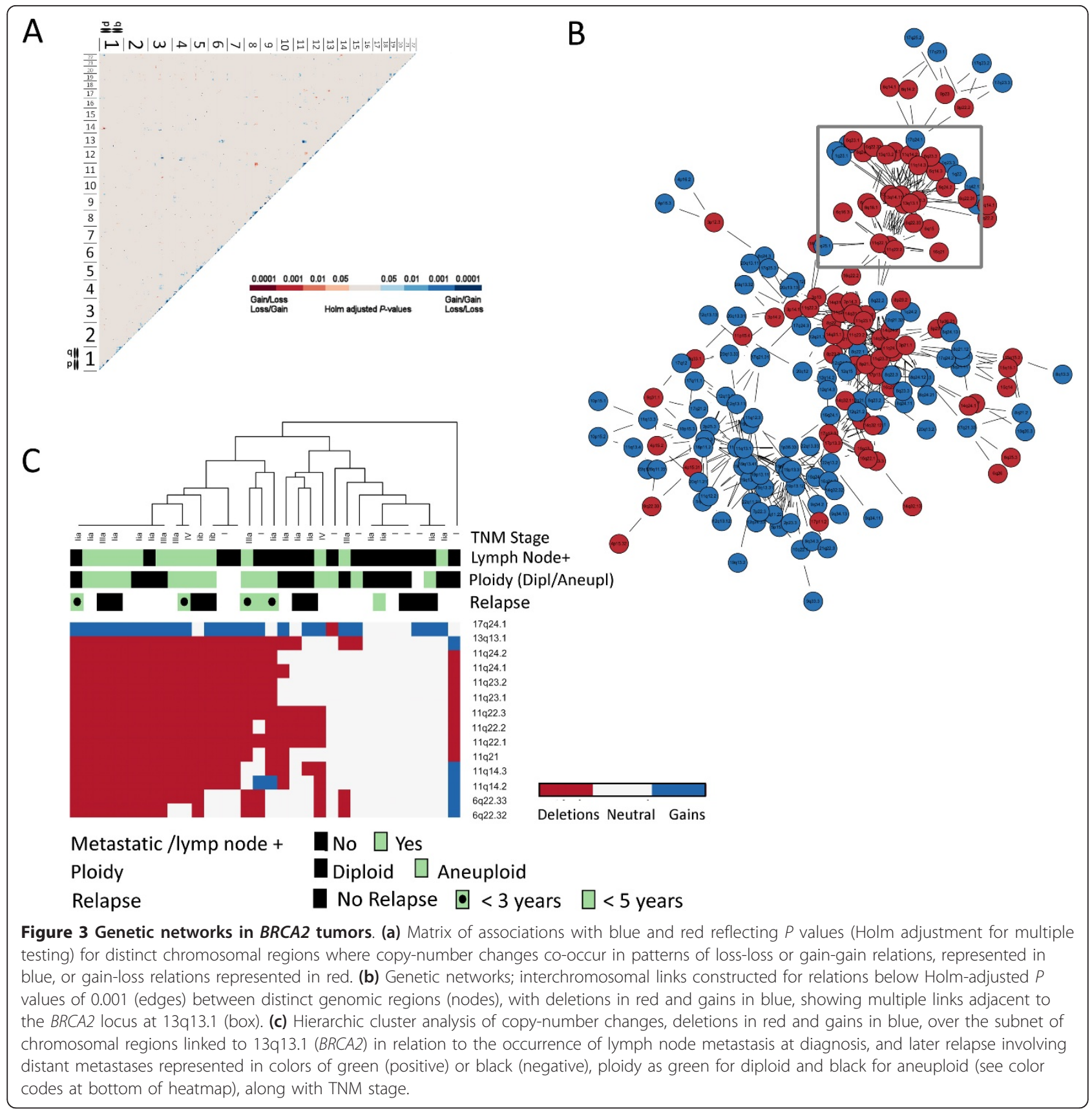

mutated tumors, having acquired changes over the $B R C A 2$-networking regions, were often identified as diploid with flow cytometry (Figure 3c).

To study this further, we compared event-frequency plots and the altered genome fractions for $B R C A 2$ tumors of the diploid and aneuploid types. This analysis shows that the amounts of genomic changes are not fewer in diploids (Figure 5a) and, although not statistically significant, that the regions affected more frequently by DNA copy-number changes in the diploid types overlap with those referred to here as the BRCA2- networking regions (Figure $5 \mathrm{~b}$ ). It is clear that the genomes of BRCA2 mutated breast cancers classified as diploid are extensively altered, and individual examples are presented here to demonstrate complex patterns of genomic changes (Figure 5c).

\section{Discussion}

In this study, we show that breast tumors from $B R C A 2$ 999del5 mutation carriers, displaying luminal- or basal/ triple-negative phenotypes (TNPs), differ with respect to patterns of copy-number changes and markers of $\mathrm{pRb} /$ 


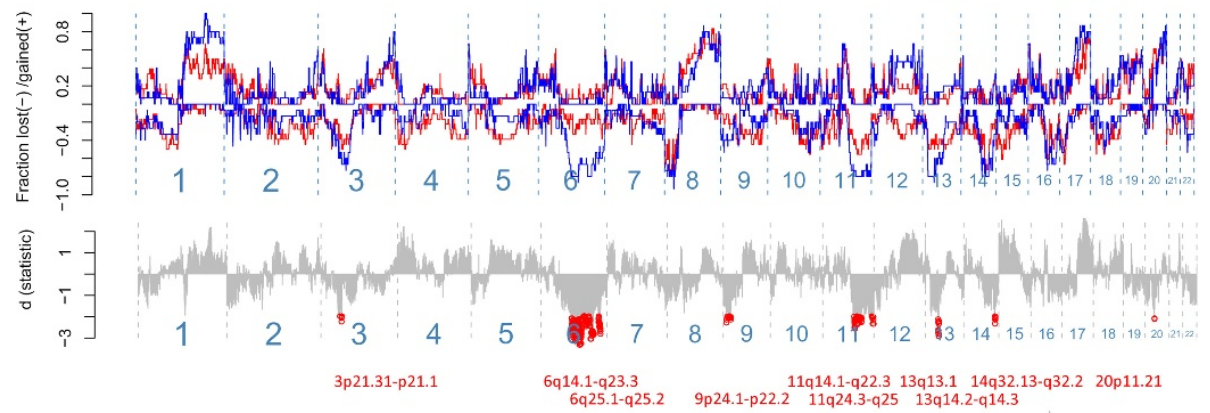

Figure 4 Two-class comparative analysis displaying event-frequency plots for BRCA2 tumors with (blue) and without (red) evidence for lymph node metastases at diagnosis. The fraction of tumors with acquired changes are represented on the $y$-axis with positive values for gains, and negative for deletions, ordered by chromosomal location on x-axis from $p$ - to q-arm, from left to right. The significance scores (d), derived from a permutation-based procedure (SAM two-class unpaired), representing the strength of association, are shown in the lower panel with relations below a false-discovery rate of 0.05 indicated in red (cytoband locations).

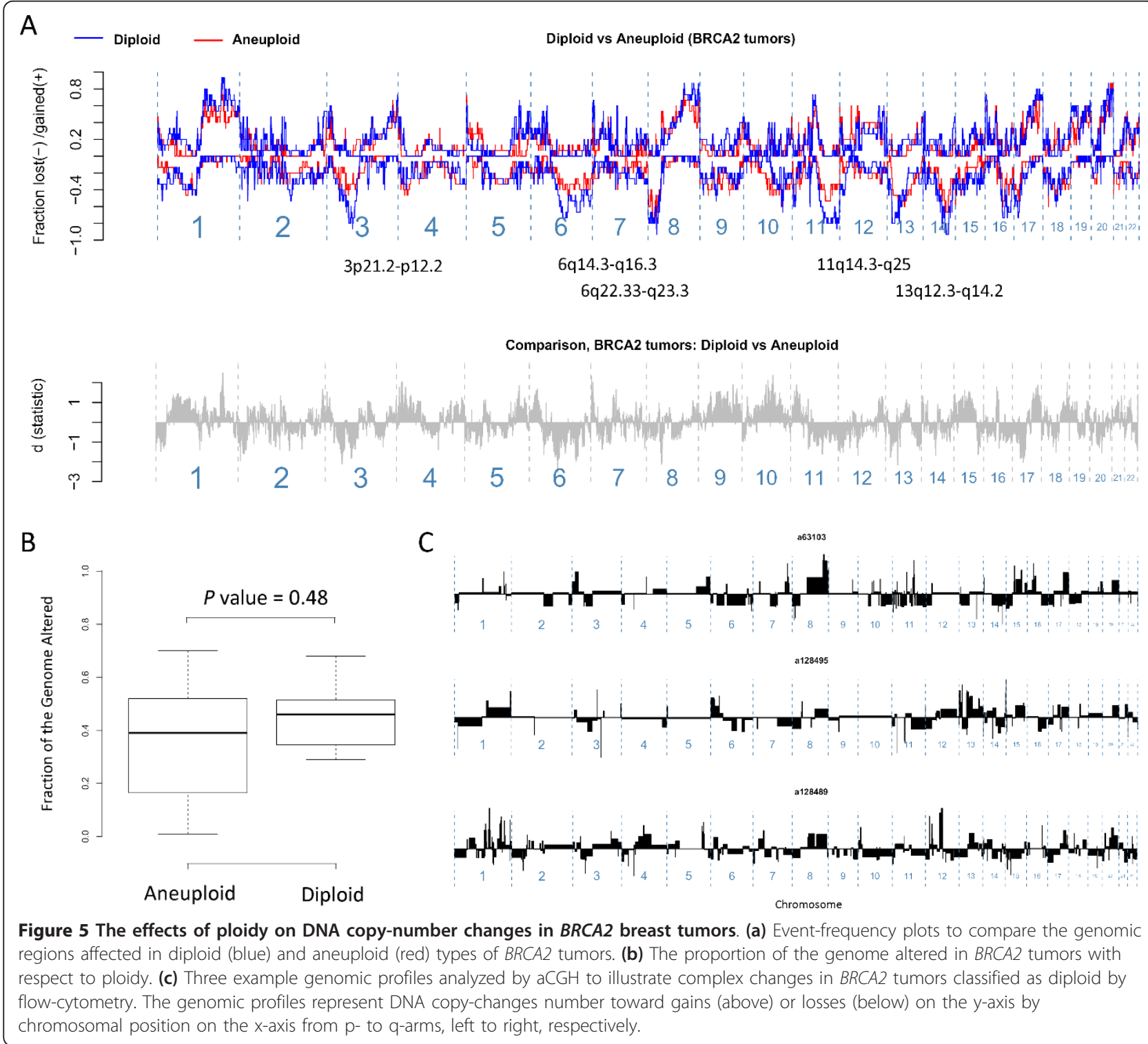


p16 pathway dysfunction, suggesting divergent paths of tumor evolution. This finding led to important observations regarding loss of the wild-type (wt) BRCA2 allele in luminal types of $B R C A 2$ tumors, where it associates with increased tumor growth rates. Furthermore, we find that deletion of the $B R C A 2 \mathrm{wt}$ allele represents a part of a larger network of co-occurring genetic changes that relate to advanced progression, involving deletions at $6 \mathrm{q} 22.32-\mathrm{q} 22.33,11 \mathrm{q} 14.2-\mathrm{q} 24.1$, as well as gains at 17q24.1. These results suggest that loss of the BRCA2wt allele is not required in tumor initiation, but rather plays an important role later in disease progression. Recently, it was demonstrated that heterozygosity for Brca2 is sufficient to promote carcinogenesis in a murine model of familial pancreatic cancer and also that LOH might not be essential for human pancreatic ductal carcinogenesis in BRCA2 999del5 mutation carriers [7]. In addition, an earlier study on breast cancer samples from carriers of different BRCA2 mutations showed retention of the $B R C A 2 w t$ allele in some cases, providing support for our conclusion [8]. We conclude that loss of the BRCA2wt allele, although not required in tumor initiation, is not a randomly occurring passenger but rather an important driver event in leading to selective growth advantages and higher clinical staging of the disease. These effects are likely indirect, resulting from accelerated mutation rates, from which advantageous mutations can arise and lead to a more aggressive phenotype.

The majority of the BRCA2-associated tumors under study displayed luminal characteristics, whereas the remaining part was of basal/triple-negative phenotype (TNP). Notably, none of the BRCA2 tumors showed overexpression or high-level amplification of the HER-2 oncogene. This subdivision of BRCA2 tumors into phenotypic subgroups is in agreement with our previous study and those of others $[14,15]$. The loss of $\mathrm{pRb}$ observed in the basal/TNP subtype of BRCA2 mutated breast tumors likely reflects acquired defects in the $R B 1$ gene. Indeed, high expression of CDKN2A (p16) gene products, indicative of functional defects in $R B 1$, has been described as a defining feature of basal-like breast cancers, and it has been suggested that this may represent an important early event in bypassing cellular stress and replicative senescence $[23,24]$. The negative-feedback loop between high p16 and low pRb has been described and is known to be the result of $\mathrm{pRb}$ binding to the CDKN2A (p16) gene promoter, leading to transcriptional repression of CDKN2A [25]. Increased expression of CDKN2A (p16) gene products arises under normal circumstances as a response to stress signals, such as telomere crisis or DNA damage. Thus, unimpeded cellular proliferation, indicated by expression of cell-cycle markers such as Ki-67, in combination with the presence of high p16 expression levels, could be indicative of abrogated p16/RB checkpoint control [23]. We found high expression of MKI67 (Ki-67) gene products, a marker for cellular proliferation, in basal/TNP $B R C A 2$ tumors, together with low $\mathrm{pRb}$ and high $\mathrm{p} 16$ levels. In contrast, the luminal subgroup of $B R C A 2$ tumors rarely showed high p16 expression levels and almost invariably showed $\mathrm{pRb}$ expression. Given the association for loss of $B R C A 2 \mathrm{wt}$ alleles with respect to the luminal phenotype, this finding would have been unexpected as the $R B 1(p R b)$ gene resides close to $B R C A 2$ on chromosome 13q. Nevertheless, the association of $\mathrm{p} 16 / \mathrm{pRb}$ dysfunction to the basal/TNP subtype, identified here in BRCA2 mutated breast tumors, is similar to that reported in sporadic tumors suggesting that the events leading to the basal/TNP phenotype in carriers and noncarriers could be the same. In this respect, it has been demonstrated that $B R C A 1$ inactivation in sporadic disease leads to development of basal/ TNP breast cancers [26,27]. In our recent report, we described the loss of $\mathrm{pRb}$, coupled with high $\mathrm{p} 16$, in BRCA1-defective breast cancers [27]. We therefore postulate that the event of acquired defects in the BRCA1 gene could have the same effect in BRCA2 mutation carriers, as seen in sporadic breast cancers. Presumably, this would alleviate selection pressure for loss of the $B R C A 2$ wt allele in BRCA2 mutation carriers. This is consistent with the data presented here, demonstrating lack of definitive $B R C A 2$ wt loss in the basal/TNP subclass of BRCA2 tumors.

Whole-genome copy-number changes in this same set of $B R C A 2$ tumors analyzed with high-resolution $(\sim 7$ $\mathrm{kbp})$ aCGH demonstrated substantial differences between luminal- and basal/TNP subtypes of BRCA2 tumors. These differences involved frequent alterations at multiple chromosome locations in luminal $B R C A 2$ tumors that were infrequently or inversely altered in basal/TNP BRCA2 tumors. Their unique patterns of copy-number changes suggest that the two phenotypic subclasses of BRCA2 tumors develop in different ways. Of particular interest here are the luminal subtypes of $B R C A 2$ tumors showing more-frequent deletions over the $B R C A 2$ gene locus. Here, gradual decreases in the proportion of $B R C A 2 w t$ alleles present within the tumor mass were correlated with increased growth rates, suggesting selective advantages for the event of BRCA2wt loss. It can be hypothesized that this relation reflects a progression pattern involving clonal expansion of tumor cells that have acquired deletion of the BRCA2wt allele. This appears contradictory to previous studies demonstrating that targeted disruption of the $\mathrm{Brca} 2$ gene negatively affects cell-cycle progression [28]. Other changes could therefore be required to overcome the deleterious effects of $B R C A 2$ deficiency. In this respect, the network 
of genetic changes affecting 6q22.32-q22.33, 11q14.2q24.1, and 17q24.1 identified in association with $B R C A 2 w t$ loss could be of critical importance in promoting survival of $B R C A 2$-defective tumor cells. This would give rise to cancer cells with $B R C A 2$ deficiency, thereby leading to accelerated mutation rates and, through the forces of natural selection, advantageous changes could accumulate and eventually lead to disease progression. Indeed, we find that the set of co-occurring changes linked to the BRCA2 region at 13q.13.1 coincide with those that associate with advanced disease progression involving metastasis to the nodes, and patient relapse involving distant metastases. Here, deletion events at chromosome $6 \mathrm{q}$ were the strongest predictors of metastatic capacity. To gain further insight into the genetic events occurring at this location, we performed fine-tiling aCGH analysis (exon-level resolution). Detailed views of changes at 6q22.33 (that is, the highest ranking of the BRCA2-linked genomic regions) suggested the involvement of genes located at, or downstream, of a breakpoint event disrupting protein tyrosine phosphatase, receptor type, $\mathrm{K}(P T P R K)$, a putative tumor suppressor gene known to be involved in TGF- $\beta$ signaling [29]. Interestingly, the 6q22.33 region has been identified as a breast cancer susceptibility locus where two candidate genes are located, that is, RING finger protein 146 (RNF146) and enoyl coenzyme A hydratase domain-containing 1 (ECHDC1) [30]. Looking at breakpoint events at chromosome $6 \mathrm{q}$ by using the fine-tiling aCGH analysis, we did not find strong evidence for gross genetic changes indicative of error-prone DNA repair through NHEJ, similar to that reported for the PTEN gene at chromosome $10 \mathrm{q}$ in BRCA1 mutated breast tumors [31]. However, it is clear that, in most cases, these events involve complex changes as they are not characterized by loss of the entire $6 \mathrm{q}$ arm. Deletions at $11 \mathrm{q}$ have been described previously in association with $B R C A 2$ breast tumors wherein aberrant expression of $A T M$ has been demonstrated [32]. However, the region at 11q14.2-q22.2, including MRE11, has not been studied previously in this respect. The subnet of genetic links associated with the BRCA2 gene locus warrants further investigation in terms of which genes are involved and whether they explain disease outcome in BRCA2 carriers and other patients with or without a family history of the disease. This could be of potential significance in defining a set of biomarkers for use in clinical settings to identify HR defects (that is, markers of BRCAness) [33].

In looking at data from flow-cytometry, we observed diploidy as a common feature of those $B R C A 2$ tumors displaying changes over the $B R C A 2$-linked regions. Clearly, this was unexpected, as diploid tumors are usually associated with genomes characterized by few or no genomic changes (that is, simple genomes) [34]. This finding has relevance to a recent study on survival in $B R C A 2$ mutation carriers, wherein tumors classified as diploid were found to be associated with fast disease progression independent of hormone receptors, histologic grade, and TNM stage (Tryggvadottir et al., 2011, unpublished data). Here, we add important insight into this, with data demonstrating complex genetic changes in genomes of BRCA2 tumors identified as diploid with flowcytometry. The presence of genomic complexity in $B R C A 2$ tumors of the diploid class demonstrates that they are pseudo-diploids. Nevertheless, the differences in disease outcome with respect to ploidy in $B R C A 2$ carriers are compelling and suggestive of divergent tumor-progression paths. In this respect, it has been shown that approximately $30 \%$ of all breast tumors classified as diploid by flow-cytometry have acquired complex patterns of genetic changes, as identified through aCGHbased method (ROMA) [34]. Importantly, the two different instability-types described (that is, firestorm and sawtooth), were associated with poor disease outcome. Thus, it seems likely that at least a certain proportion of tumors classified as diploid by conventional flow-cytometry could be promoted by acquired defects in components of the HR machinery, possibly involving the BRCA2 gene.

Inhibitors of PARP1 gene products have been shown to kill $B R C A 1$ - or BRCA2-defective cells selectively, with no effects on heterozygous cells, and such inhibitors are currently being tested in clinical trials [35]. Our results could have clinical implications regarding the use of PARP inhibitors, with observations demonstrating late involvement for loss of the BRCA2wt allele. In this respect, PARP inhibitors will probably not be sufficient alone (that is, as monotherapy), for treatment of $B R C A 2$ carriers. Nevertheless, the risk of progression toward advanced disease in the event of BRCA2wt allele loss is of considerable concern, and our results therefore strongly support adjuvant use of PARP inhibitors in standard treatment of all BRCA2 mutation carriers.

\section{Conclusions}

In conclusion, our results demonstrate phenotypic heterogeneity of breast cancers arising in carriers of the same 999del5 BRCA2 mutation. We show that the luminal- and basal/TN phenotypes develop through divergent tumor evolutionary paths. Here, loss of the BRCA2 wild-type allele occurs more frequently in the luminal subtype, where it correlates with increased tumor growth rates. Furthermore, the event of $B R C A 2$ wt allele loss occurs in the context of other genetic changes, involving deletions at $6 \mathrm{q}, 11 \mathrm{q}$, and copy-number gains at $17 \mathrm{q}$. These changes, including deletions over the $B R C A 2$ gene locus, were found to be associated with higher clinical staging at diagnosis involving metastasis 
to the lymph nodes, and correlated with patient relapse. These observations could explain why BRCA2 carriers have predilection for developing breast cancers of the luminal $\mathrm{B}$ phenotype. The findings presented here, suggesting that loss of the $B R C A 2 \mathrm{wt}$ allele is a late, rather than early, event in progression toward metastatic disease, have clinical relevance supporting adjuvant, and not single-agent, use of PARP inhibitors in treatment of BRCA2 carriers.

\section{Additional material}

Additional file 1: Phenotype and clinical parameters. Table listing tumor phenotype and clinical parameters including breast cancer subtype, histologic grade, and TNM stage.

Additional file 2: Antibodies for expression analysis on TMAs. Table listing the antibodies used for immunohistochemistry on tissue microarrays (TMAs).

Additional file 3: The expression of $\mathrm{Ki}-67, \mathrm{p} 16$, and $\mathrm{pRb}$ in $B R C A 2$ mutated breast cancers by phenotype. Expression of Ki-67, p16, and pRb by $I H C$ on tissue microarrays (TMAs) in subtypes of BRCA2 breast tumors. (a) The distribution of Ki-67 expression levels, reflecting cellular proliferation, compared between BRCA2 tumors of basal/triple-negative and luminal phenotypes. Example $\mathrm{HC}$ analysis for Ki-67 shows higher proportion of positive cells in BRCA2 tumors of triple-negative (lower panel) compared with luminal phenotypes (upper panel). (b) Expression of p16 (CDKN2A) in BRCA2 tumors by phenotype with low expression of $\mathrm{pRb}$ (IHC null) indicated, see Table 1 for details. Examples show representative BRCA2 tumors of luminal- (upper panel) and triplenegative (lower panel) phenotypes.

Additional file 4: The complete set of links identified in breast cancers graphically represented as node-and-edge graphs, shown here separately for those derived from $B R C A 2$ carriers and sporadic cases. Genetic networks constructed for relations below Holm-adjusted $P$ values of 0.001 (edges) between distinct genomic regions (nodes), with deletions in red and gains in blue. The links identified, reflecting cooccurring genetic changes, were split into sets of inter- and intrachromosomal links characterized as those involving distinct chromosomes (inter, left on figure) or distinct arms on the same chromosome (intra, right on figure), respectively. (a) The genetic networks constructed for BRCA2 mutated breast cancers, and (b) those arising in the sporadic setting.

Additional file 5: BRCA2 wild-type allele specific qPCR examined with respect to DNA copy-number changes. Deletion of wild-type BRCA2 alleles by TaqMan $\mathrm{PPCR}$ analysis were examined on a continuous scale in relation with the genome-wide segmented $\mathrm{aCGH} \log _{2}$ ratios by using a regression model with repeated permutations to address the problem of multiple testing, as implemented in SAM (quantitative analysis). The significance scores ( $r$ ) derived from this analysis are plotted on the $y$-axis for each genomic location ordered from $p$ - to q-arm on the $x$-axis, from left to right, with relations below a false-discovery rate of 0.0001 indicated by red dots.

\section{Additional file 6: Detailed analysis of event frequencies at} chromosome $6 \mathrm{q}$ in BRCA2 mutated breast cancers. Analysis of DNA copy-number changes occurring at chromosome 6 in BRCA2 tumors. (a) Top: Comparison for the frequency of events in BRCA2 tumors with and without evidence for metastatic spread to the lymph nodes or other sites at diagnosis, a trait reflecting metastatic capacity, represented in red and orange, respectively (see legend at the top right corner). Bottom: Zooming in on the frequency of events at 6q22.33, selected for further analysis, as this region strongly associates with metastatic capacity in $B R C A 2$ tumors while also being linked to deletions over the BRCA2 gene locus at 13q13.1. (b) Top: Example of fine-tiling aCGH analysis (exon-level resolution) for chromosome 6 in one BRCA2 breast tumor where aCGH $\log _{2}$ ratios are plotted on the $y$-axis in order of nucleotide position on the $x$-axis. Dashed vertical lines represent locations of cytoband boundaries, as indicated below, and solid horizontal red lines represent output derived from CBS analysis for detecting copy-number changes with negative values of segmented $\mathrm{aCGH} \log _{2}$ ratios reflecting change toward deletions, and positive values as change toward copy-number gains. Bottom: Enlarged, detailed view of the entire $6 q 22.33$ region in this tumor shows a breakpoint event occurring nearby the PTPRK gene, a frequent site of deletion events in metastatic BRCA2 tumors (see data in Figure $5 \mathrm{a}$, bottom panel) affecting four other genes within this cytoband (EEF1DP5, LAMA2, ARHGAP18, and C6orf191).

Additional file 7: aCGH analysis using fine-tiling arrays (400 bp) for chromosome 6 in BRCA2 mutated breast cancers. Fine-tiling aCGH analysis (exon-level resolution) covering chromosome 6, with about one probe for each $400 \mathrm{bp}$, was performed to reanalyze and confirm events at this chromosome with greater clarity in three of the BRCA2 tumors. The $\mathrm{aCGH} \log _{2}$ ratios are plotted on the $y$-axis in order of nucleotide position on the $x$-axis, with dashed vertical lines representing locations of cytoband boundaries, as indicated below. Solid horizontal red lines represent output derived from CBS analysis for detecting copy-number changes with negative values of segmented aCGH $\log _{2}$ ratios reflecting change toward deletions, and positive values as change toward copynumber gains.

\section{Abbreviations}

CGH: comparative genomic hybridization; DSB: double-stranded break; HR: homologous recombination; IHC: immunohistochemistry; LumA: Luminal-A; LumB: Luminal-B; NHEJ: nonhomologous end joining; SSA: single-strand annealing; TMA: tissue microarrays; TNP: triple-negative phenotype.

\section{Acknowledgements}

The authors thank Holmfridur Hilmarsdottir for BRCA2 germline mutation screening and technical assistance. We also thank the staff at Roche NimbleGen Systems in Iceland for assistance with the aCGH analysis. This work was funded by Eimskipafelag University Fund (OAS), Minningarsjodur Bergthoru Magnusdottur and Jakobs J Bjarnasonar (OAS), Gongum Saman (OAS), Icelandic Cancer Research Fund SKI (OAS), Icelandic Centre for Research RANNIS (OAS, JGJ, OTJ, JEE), and The University of Iceland Research Fund (OAS, JEE).

\section{Author details}

${ }^{1}$ Cancer Research Laboratory, Faculty of Medicine, University of Iceland, Vatnsmyrarvegur 16, Reykjavik, Iceland. Department of Pathology, Landspitali University Hospital, Hringbraut, Reykjavik, 101, Iceland.

${ }^{3}$ Department of Oncology, Landspitali University Hospital, Hringbraut, Reykjavik, 101, Iceland. 'The Icelandic Cancer Registry, Skogarhlid 8, Reykjavik, 101, Iceland. ${ }^{5}$ Roche NimbleGen, Inc., Vínlandsleið 2-4, Reykjavik, 113, Iceland.

\section{Authors' contributions}

OAS contributed to the study design and performed the aCGH analysis along with statistical analysis, data mining, and writing of the manuscript. OAS and JGJ selected tumor tissue for TMAs. KO constructed the TMAs and performed IHC analysis. OAS and JGJ scored the IHC results. JGJ scored histologic grade and TNM staging. OTJ contributed clinical data, and SV contributed to the aCGH analysis. HB and SKB performed the TaqMan BRCA2 allele-specific quantitative PCR (qPCR). JEE conceived of the study and was in charge of its design and the coordination and writing of the manuscript. All authors read and approved of the manuscript.

\section{Competing interests}

The authors declare that they have no competing interests.

Received: 25 January 2011 Revised: 12 July 2011

Accepted: 29 September 2011 Published: 29 September 2011

\section{References}

1. Oldenburg RA, Meijers-Heijboer H, Cornelisse CJ, Devilee P: Genetic susceptibility for breast cancer: how many more genes to be found? Crit Rev Oncol Hematol 2007, 63:125-149. 
2. Murphy $C G$, Moynahan ME: BRCA gene structure and function in tumor suppression: a repair-centric perspective. Cancer J 2010, 16:39-47.

3. Gudmundsdottir K, Ashworth A: The roles of BRCA1 and BRCA2 and associated proteins in the maintenance of genomic stability. Oncogene 2006, 25:5864-5874.

4. Yu VP, Koehler M, Steinlein C, Schmid M, Hanakahi LA, van Gool AJ, West SC, Venkitaraman AR: Gross chromosomal rearrangements and genetic exchange between nonhomologous chromosomes following BRCA2 inactivation. Genes Dev 2000, 14:1400-1406.

5. Gretarsdottir S, Thorlacius S, Valgardsdottir R, Gudlaugsdottir S, Sigurdsson S, Steinarsdottir M, Jonasson JG, Anamthawat-Jonsson K, Eyfjord JE: BRCA2 and p53 mutations in primary breast cancer in relation to genetic instability. Cancer Res 1998, 58:859-862.

6. Collins N, McManus R, Wooster R, Mangion J, Seal S, Lakhani SR, Ormiston W, Daly PA, Ford D, Easton DF, et al: Consistent loss of the wild type allele in breast cancers from a family linked to the BRCA2 gene on chromosome 13q12-13. Oncogene 1995, 10:1673-1675.

7. Skoulidis F, Cassidy LD, Pisupati V, Jonasson JG, Bjarnason H, Eyfjord JE, Karreth FA, Lim M, Barber LM, Clatworthy SA, Davies SE, Olive KP, Tuveson DA, Venkitaraman AR: Germline Brca2 heterozygosity promotes Kras(G12D)-driven carcinogenesis in a murine model of familial pancreatic cancer. Cancer Cell 2010, 18:499-509.

8. King TA, Li W, Brogi E, Yee CJ, Gemignani ML, Olvera N, Levine DA, Norton L, Robson ME, Offit K, Borgen PI, Boyd J: Heterogenic loss of the wild-type BRCA allele in human breast tumorigenesis. Ann Surg Oncol 2007, 14:2510-2518.

9. Sorlie T, Tibshirani R, Parker J, Hastie T, Marron JS, Nobel A, Deng S, Johnsen H, Pesich R, Geisler S, Demeter J, Perou CM, Lønning PE, Brown PO, Børresen-Dale AL, Botstein D: Repeated observation of breast tumor subtypes in independent gene expression data sets. Proc Natl Acad Sci USA 2003, 100:8418-8423.

10. Bergamaschi A, Kim YH, Wang P, Sorlie T, Hernandez-Boussard T, Lonning PE, Tibshirani R, Borresen-Dale AL, Pollack JR: Distinct patterns of DNA copy number alteration are associated with different clinicopathological features and gene-expression subtypes of breast cancer. Genes Chromosomes Cancer 2006, 45:1033-1040.

11. Chin K, DeVries S, Fridlyand J, Spellman PT, Roydasgupta R, Kuo WL, Lapuk A, Neve RM, Qian Z, Ryder T, Chen F, Feiler H, Tokuyasu T, Kingsley C, Dairkee S, Meng Z, Chew K: Genomic and transcriptional aberrations linked to breast cancer pathophysiologies. Cancer Cell 2006, 10:529-541.

12. Cheang MC, Chia SK, Voduc D, Gao D, Leung S, Snider J, Watson M, Davies S, Bernard PS, Parker JS, Perou CM, Ellis MJ, Nielsen TO: Ki67 index, HER2 status, and prognosis of patients with luminal B breast cancer. J Natl Cancer Inst 2009, 101:736-750.

13. Cheang MC, Voduc D, Bajdik C, Leung S, McKinney S, Chia SK, Perou CM, Nielsen TO: Basal-like breast cancer defined by five biomarkers has superior prognostic value than triple-negative phenotype. Clin Cancer Res 2008, 14:1368-1376.

14. Melchor L, Honrado E, Garcia MJ, Alvarez S, Palacios J, Osorio A, Nathanson KL, Benitez J: Distinct genomic aberration patterns are found in familial breast cancer associated with different immunohistochemical subtypes. Oncogene 2008, 27:3165-3175.

15. Stefansson OA, Jonasson JG, Johannsson OT, Olafsdottir K, Steinarsdottir M, Valgeirsdottir S, Eyfjord JE: Genomic profiling of breast tumours in relation to BRCA abnormalities and phenotypes. Breast Cancer Res 2009, 11:R47.

16. Thorlacius S, Olafsdottir G, Tryggvadottir L, Neuhausen S, Jonasson JG, Tavtigian SV, Tulinius H, Ogmundsdottir HM, Eyfjord JE: A single BRCA2 mutation in male and female breast cancer families from Iceland with varied cancer phenotypes. Nat Genet 1996, 13:117-119.

17. Parkinson H, Sarkans U, Kolesnikov N, Abeygunawardena N, Burdett T, Dylag M, Emam I, Farne A, Hastings E, Holloway E, Kurbatova N, Lukk M, Malone J, Mani R, Pilicheva E, Rustici G, Sharma A, Williams E, Adamusiak T, Brandizi M, Sklyar N, Brazma A: ArrayExpress update: an archive of microarray and high-throughput sequencing-based functional genomics experiments. Nucleic Acids Res, 39 Database: D1002-1004.

18. Germer S, Higuchi R: Homogeneous allele-specific PCR in SNP genotyping. Methods Mol Biol 2003, 212:197-214.

19. Tusher VG, Tibshirani R, Chu G: Significance analysis of microarrays applied to the ionizing radiation response. Proc Natl Acad Sci USA 2001, 98:5116-5121
20. Karolchik D, Hinrichs AS, Kent WJ: The UCSC genome browser. Curr Protoc Bioinformatics 2009, Chapter 1:Unit1-4.

21. Beresford MJ, Wilson GD, Makris A: Measuring proliferation in breast cancer: practicalities and applications. Breast Cancer Res 2006, 8:216.

22. Natrajan R, Lambros MB, Rodríguez-Pinilla SM, Moreno-Bueno G, Tan DS, Marchió C, Vatcheva R, Rayter S, Mahler-Araujo B, Fulford LG, Hungermann D, Mackay A, Grigoriadis A, Fenwick K, Tamber N, Hardisson D, Tutt A, Palacios J, Lord CJ, Buerger H, Ashworth A, Reis-Filho JS: Tiling path genomic profiling of grade 3 invasive ductal breast cancers. Clin Cancer Res 2009, 15:2711-2722.

23. Gauthier ML, Berman HK, Miller C, Kozakeiwicz K, Chew K, Moore D, Rabban J, Chen YY, Kerlikowske K, TIsty TD: Abrogated response to cellular stress identifies DCIS associated with subsequent tumor events and defines basal-like breast tumors. Cancer Cell 2007, 12:479-491.

24. Subhawong AP, Subhawong T, Nassar H, Kouprina N, Begum S, Vang R, Westra WH, Argani P: Most basal-like breast carcinomas demonstrate the same Rb-/p16+ immunophenotype as the HPV-related poorly differentiated squamous cell carcinomas which they resemble morphologically. Am J Surg Pathol 2009, 33:163-175.

25. Hara E, Smith R, Parry D, Tahara H, Stone S, Peters G: Regulation of p16CDKN2 expression and its implications for cell immortalization and senescence. Mol Cell Biol 1996, 16:859-867.

26. Hedenfalk I, Duggan D, Chen Y, Radmacher M, Bittner M, Simon R, Meltzer P, Gusterson B, Esteller M, Kallioniemi OP, Wilfond B, Borg A, Trent J, Raffeld M, Yakhini Z, Ben-Dor A, Dougherty E: Gene-expression profiles in hereditary breast cancer. N Engl J Med 2001, 344:539-548.

27. Stefansson OA, Jonasson JG, Olafsdottir K, Hilmarsdottir $\mathrm{H}$, Olafsdottir $\mathrm{G}$ Esteller M, Johannsson OT, Eyfjord JE: CpG island hypermethylation of BRCA1 and loss of pRb as co-occurring events in basal/triple-negative breast cancer. Epigenetics 2011, 6:638-649.

28. Patel KJ, Yu VP, Lee H, Corcoran A, Thistlethwaite FC, Evans MJ, Colledge WH, Friedman LS, Ponder BA, Venkitaraman AR: Involvement of Brca2 in DNA repair. Mol Cell 1998, 1:347-357.

29. Wang SE, Wu FY, Shin I, Qu S, Arteaga CL: Transforming growth factor \{beta\} (TGF-\{beta\})-Smad target gene protein tyrosine phosphatase receptor type kappa is required for TGF-\{beta\} function. Mol Cell Biol 2005, 25:4703-4715.

30. Gold B, Kirchhoff T, Stefanov S, Lautenberger J, Viale A, Garber J, Friedman E, Narod S, Olshen AB, Gregersen P, Kosarin K, Olsh A, Bergeron J, Ellis NA, Klein RJ, Clark AG, Norton L: Genome-wide association study provides evidence for a breast cancer risk locus at $6 \mathrm{q} 22.33$. Proc Natl Acad Sci USA 2008, 105:4340-4345.

31. Saal LH, Gruvberger-Saal SK, Persson C, Lovgren K, Jumppanen M, Staaf J, Jonsson G, Pires MM, Maurer M, Holm K, Koujak S, Subramaniyam S, VallonChristersson J, Olsson H, Su T, Memeo L: Recurrent gross mutations of the PTEN tumor suppressor gene in breast cancers with deficient DSB repair. Nat Genet 2008, 40:102-107.

32. Tommiska J, Bartkova J, Heinonen M, Hautala L, Kilpivaara O, Eerola H, Aittomaki K, Hofstetter B, Lukas J, von Smitten K, Blomqvist C, Ristimäki A, Heikkilä P, Bartek J, Nevanlinna H: The DNA damage signalling kinase ATM is aberrantly reduced or lost in BRCA1/BRCA2-deficient and ER/PR/ ERBB2-triple-negative breast cancer. Oncogene 2008, 27:2501-2506.

33. Turner N, Tutt A, Ashworth A: Hallmarks of "BRCAness" in sporadic cancers. Nat Rev Cancer 2004, 4:814-819.

34. Hicks J, Krasnitz A, Lakshmi B, Navin NE, Riggs M, Leibu E, Esposito D, Alexander J, Troge J, Grubor V, Yoon S, Wigler M, Ye K, Børresen-Dale AL, Naume B, Schlicting E, Norton L, Hägerström T: Novel patterns of genome rearrangement and their association with survival in breast cancer. Genome Res 2006, 16:1465-1479.

35. Fong PC, Boss DS, Yap TA, Tutt A, Wu P, Mergui-Roelvink M, Mortimer $P$ Swaisland H, Lau A, O'Connor MJ, Ashworth A, Carmichael J, Kaye SB, Schellens JH, de Bono JS: Inhibition of poly(ADP-ribose) polymerase in tumors from BRCA mutation carriers. N Engl J Med 2009, 361:123-134.

\section{doi:10.1186/bcr3020}

Cite this article as: Stefansson et al:: Genomic and phenotypic analysis of $B R C A 2$ mutated breast cancers reveals co-occurring changes linked to progression. Breast Cancer Research 2011 13:R95. 